\title{
An Improved Danger Sector Model for Identifying the Collision Risk of Encountering Ships
}

\author{
Zihao Liu ${ }^{\circledR}$, Zhaolin $\mathrm{Wu}^{*}$ and Zhongyi Zheng \\ Navigation College, Dalian Maritime University, Dalian 116026, China; zihaoliu0407@gmail.com (Z.L.); \\ dlzzyi@sina.com (Z.Z.) \\ * Correspondence: wuzl@dlmu.edu.cn
}

Received: 15 July 2020; Accepted: 13 August 2020; Published: 15 August 2020

\begin{abstract}
In order to avoid collision, ships usually take collision avoidance manoeuvres, such as course alteration. However, the effect of such a manoeuvre is influenced by ship manoeuvrability. This paper proposed an improved danger sector model to identify the collision risk between two encountering ships. The proposed model is improved from the danger sector model, which is based on a course alteration manoeuvre by taking ship manoeuvrability into consideration. To involve ship manoeuvrability in the proposed model, the turning circle of a ship is determined when it calculates the size of the danger sector. For validating the proposed model, the Automatic Identification System (AIS) data in the northern Yellow Sea of China were used to carry out some experiments of different encountering scenarios. The results show that the proposed improved danger sector model can identify the collision risk between two encountering ships effectively and has advantages compared with the original danger sector model. The proposed model can help mariners and maritime surveillance operators have a more accurate and effective assessment of ship collision risk in the water area, which can contribute to the improvement of navigational safety.
\end{abstract}

Keywords: collision risk; danger sector; ship manoeuvrability; turning circle; navigational safety

\section{Introduction}

Maritime transportation plays an important role in global trade. With the increasing demand of transportation in the past decades, maritime traffic is also becoming busier [1,2]. The great amount of maritime traffic may cause maritime accidents such as collisions [3]. The ship and maritime surveillance sector has endeavoured to prevent collision accidents so as to ensure navigational safety [4]. For avoiding collision at sea, ships usually take collision avoidance manoeuvres when in a relatively dangerous situation, such as course alteration manoeuvres. Since different ships may have different performances, the difficulties of them conducting such collision avoidance manoeuvres are varying [5]. A ship featured with high manoeuvrability can complete the collision avoidance manoeuvre much easier and more efficiently [6]. For example, it can alter the target course within a relatively short period or within a relatively short distance. Hence, ship manoeuvrability is important to the collision avoidance manoeuvre. For reducing collision accidents at sea, the identification of collision risks has been widely researched. The accurate quantification of collision risk can help the mariners on ship or the maritime surveillance operators become familiar with encountering situations and assist them in making subsequent decisions [7]. As ship manoeuvrability is crucial to collision avoidance manoeuvres and collision risk has a relationship with collision avoidance, it is necessary to take ship manoeuvrability into consideration in collision risk identification.

There have been many studies focusing on the modeling of collision risk between encountering ships, which is very useful for reducing collision accidents at sea. At the early stage, two crucial parameters in Automatic Radar Plotting Aid (ARPA) are used to assess the collision risk together, 
which are Distance at Closest Point of Approach (DCPA) and Time to Closest Point of Approach (TCPA) [8-10]. These two parameters are proved to have a negative correlation with collision risk. The method can identify the risk of collision efficiently; however, the accuracy of the results may be affected as a result of the limited factors considered. After that, some scholars model collision risk based on fuzzy mathematics. Many other factors related to collision risk can be involved in the modeling of collision risk apart from DCPA and TCPA. Kao et al. [11] include ship speed, ship length, and sea state into its collision risk identification model. By inputting these parameters in a fuzzy logic system, the guarding ring of the ship can be obtained to represent the collision risk. Schinas [12] highlights the importance of the using Multi-Criteria Decision Making (MCDM) methods and decision-making tools and examining them in the maritime safety assessment. The applicability of the techniques is discussed in the maritime environment in relationship to established methods. In addition to DCPA and TCPA, the Variation of a Compass Direction (VCD) from the Vessel Traffic Service (VTS) viewpoint is introduced in the collision risk model based on a fuzzy logic system [13]. These parameters can obtained from RADAR in the VTS centre. Zhang et al. [14] propose a new collision risk indicator called Vessel Collision Risk Operator (VCRO), which is related to ship speed, distance, and relative bearing. The indicator is used as an input together with its varying rate and ship size with time in a fuzzy logic system to model the risk of collision [15]. Although the method based on fuzzy mathematic can involve more factors, it also has limitation because of its subjectivity in building a fuzzy rule base. Recently, with the wide access to Automatic Identification System (AIS) data, there are more methods proposing modeling the collision risk between encountering ships. Chen et al. [16] propose a Time Discrete Non-linear Velocity Obstacle method to detect collision candidates so as to assess the risk of collision. In detecting collision candidates, the encountering of ships is considered as a process. The historical data are used to check the effectiveness of the candidates detected. Fang et al. [17] propose an AIS-based method to calibrate the collision risk of near-miss ships. The collision risk is identified by using ship speed and course patterns. After obtaining the robust collision risk of near-miss ships, the high-risk region can be detected by their geographical distributions. In [18], the maritime traffic complexity model is improved by including ship length, ship movement, distance, and crossing angle. Based on the improved complexity model, the collision risk of encountering ships can be identified by a clustering method with a new defined distance. Liu et al. [19] propose a cooperative game approach for assessing the collision risk of multi-vessel encountering. In modeling the risk, a new collision risk indicator called the danger sector is established based on the collision avoidance manoeuvre and ship domain. The indicator can be used to identify the collision risk of encountering ships, and it is the basis of the proposed multi-vessel encountering collision risk model. In [20], a novel framework of real-time collision risk prediction is proposed based on the Recurrent Neural Network (RNN) approach. The collision risk is firstly identified by the regional collision risk identification approach in [21], which is based on the encountering of ships. Then, the collision risk of the specific water area is predicted by an optimised RNN method in a short time. The above-mentioned methods are all useful in identifying the collision risk between encountering ships, and it can contribute to the improvement of navigational safety. However, most of them do not consider ship manoeuvrability when assessing collision risk. This may affect the accuracy of the results in some cases. For overcoming this problem, this paper aims to propose a collision risk identification model that takes ship manoeuvrability into consideration. The proposed model is improved from the danger sector model, which is established based on course alteration manoeuvres. After including ship manoevurability into the proposed model, it is capable of identifying the collision risk between two encountering ships more effectively and accurately. It is helpful for the mariners on the ship and the maritime surveillance operators to recognise the risk of collision, which can contribute to the safety of navigation. The reminder of the paper is arranged as follows. In Section 2, after introducing the danger sector and ship manoeuvrability, the improved danger sector model is established. For validating the proposed model and proving its advantages, some experiments were carried out by using the AIS data in the northern Yellow Sea of China. In Section 4, the proposed model 
of an improved danger sector is discussed and analysed, and some limitations of the proposed model are summarised. In Section 5, the conclusion is drawn, and the limitations that can be researched in the future are presented.

\section{The Improved Danger Sector Model}

\subsection{Danger Sector Model}

In [19], the danger sector model is proposed as a new collision risk indicator to represent the collision risk between two vessels. Just as its name implies, the danger sector is a sector area that can reflect the danger of collision of the ship. The danger sector is established based on the ship domain and collision avoidance manoeuvre of course alteration. It is defined as the sector that is composed of plenty of course lines, and the ship will intrude the target ship's domain when adopting these courses. An exemplary danger sector of two ships in a head-on encountering is shown in Figure 1. As the distance between the two ships decreases, the danger sector will become bigger, and the collision risk between the two ships will increase. At relatively close distance, it becomes more difficult for the ship to conduct a collision avoidance manoeuvre by altering course, and thus leading to the incrementing collision risk. The relationship between the danger sector and collision risk can be expressed as the following equation:

$$
C R \propto R a d,
$$

where $C R$ refers to collision risk, and $R a d$ refers to danger sector, because it is a sector with the unit of radians.

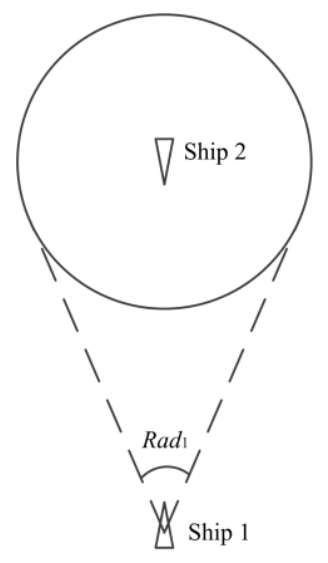

(a)

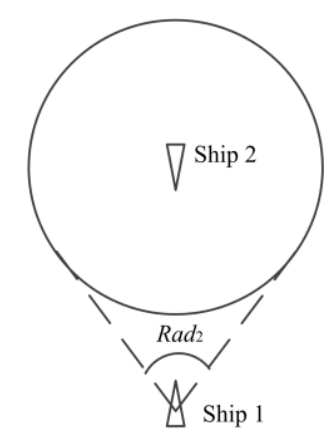

(b)

Figure 1. An exemplary danger sector of two ships in a head-on encountering (a) Scenario 1; (b) Scenario 2.

The danger sector of a ship can be divided into two parts, which are the port section and starboard section. The two sections are corresponding to the course alteration manoeuvre to the two different sides. As indicated in Figure 1, in order to avoid intruding on Ship 2's domain, Ship 1 can choose the left alteration or right alteration. Although altering to starboard is preferred in a head-on encountering in reality, both alterations are considered in assessing the collision risk of the scenario. The port section and starboard section can finally form a danger sector. The bigger the danger sector, the greater the amplitude of the course alteration, and the higher the collision risk.

\subsection{An Improved Danger Sector Model Considering Ship Manoeuvrability}

Ship manoeuvrability can be considered as the responsiveness to the manoeuvres conducted by mariners. The manoeuvrability of a ship is crucial to its safe and efficient manoeuvring. If a ship is 
featured with good manoeuvrability, it is capable of maintaining the motion conveniently and stably and changing the motion rapidly and accurately [6].

Ship manoeuvrability includes the manoeuvrability of speed changing, the manoeuvrability of turning, and the manoeuvrability of course maintaining. In this paper, the turning manoeuvrability of a ship is focused on, as it is directly related to the modeling of the danger sector, which is based on the course alteration manoeuvre, namely the turning manoeuvre. Ship turning manoeuvrability refers to the manoeuvrability of changing into a steady turning circle after manipulating the rudder. In other words, it is the manoeuvrability of course alteration. The most important concept in ship-turning manoeuvrability is the turning circle. It is a circle depicted by the mass centre of a ship after a course-altering manoeuvre [22]. The pivot point is another important centre in the turning circle. Different from the mass centre, the pivot point moves continuously in the first two phases of the turning circle, and it tends to fix at a point in the third phase. At the pivot point, the linear velocity and drift angle are both 0 . However, as the ship is represented by the AIS position point, the mass centre and the pivot point of the ship converge to the same point in the proposed model. An exemplary ship turning circle is shown in Figure 2.

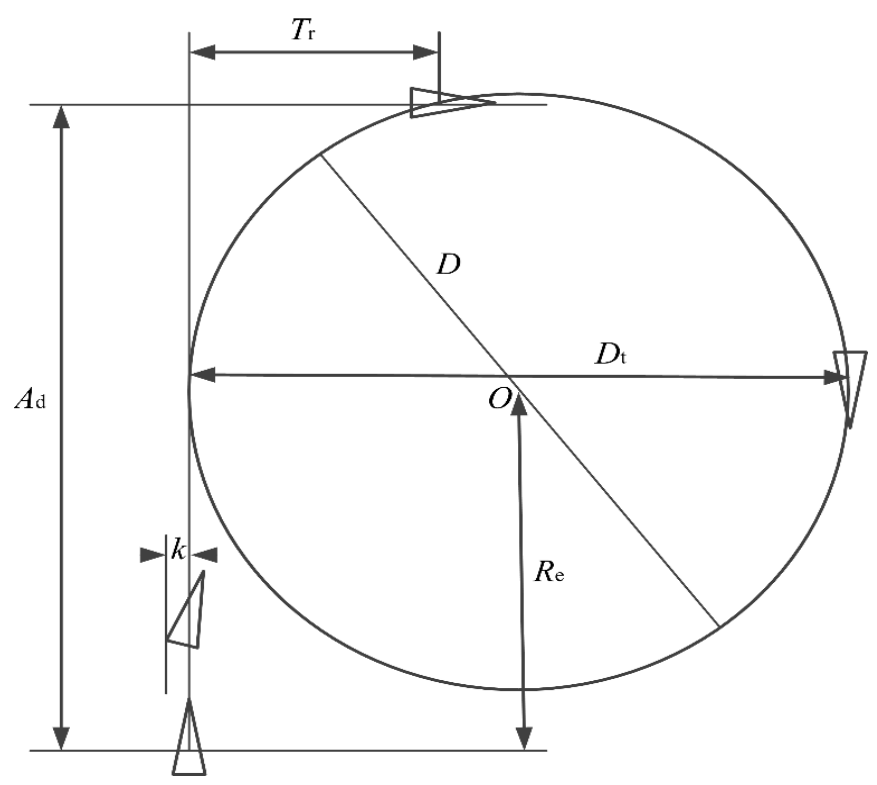

Figure 2. An exemplary ship turning circle.

Among all the parameters of the turning circle, the advance (Ad) and the tactical diameter $(D \mathrm{t})$ are the most important, as they are crucial to determining the size of the turning circle. According to the standards for ship manoeuvrability issued by the International Maritime Organization (IMO), the advance $A \mathrm{~d}$ should not exceed 4.5 ship lengths, and the tactical diameter $D t$ should not exceed 5 ship lengths in the turning circle manoeuvre [23]. These criteria are important to determine the size of the ship turning circle, and it is adopted as a criteria in determining the turning circle in the danger sector model.

As introduced in Section 2.1, the danger sector model is established based on the course alteration manoeuvre of a ship. In the model, the course alteration is considered as an instantaneous manoeuvre. In other words, when assessing the danger sector of a ship, it is assumed that the course of the ship can be altered instantaneously, and the position of the ship is not changed. However, the course alteration manoeuvre, namely the turning manoeuvre, is a process in reality. In a turning circle, a ship will go through three different phases before reaching the target course, which are the manoeuvring phase, evolutionary phase, and steady turning phase [22]. It will lead to changing the ship's position. The ship will not maintain its original position when reaching the target course, as shown in Figure 3. 


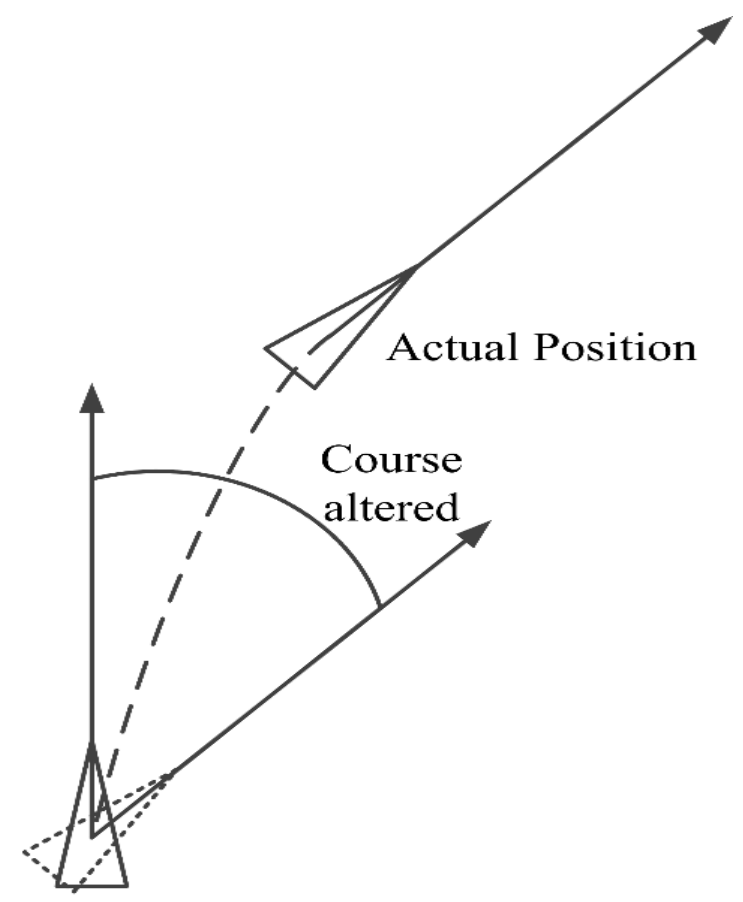

\section{Original Position}

Figure 3. The illustration of position change after altering course.

As for the danger sector model, ship should alter to the port or starboard side to avoid intruding the target ship's domain. When determining the size of the danger sector, namely the marginal course lines of the sector, the position of the ship is assumed to not change in the original model, and the course alteration can be conducted instantaneously. Actually, as an impact of ship manoeuvrability, the position of the ship is supposed to change after turning to the marginal course of the danger sector. This change of ship position may lead to the situation in which the ship is not capable of avoiding intruding the target ship's domain by adopting the marginal course of the danger sector, as shown in Figure 4. In other words, if the ship manoeuvring is not considered in the danger sector model, the results may be not accurate enough: normally, the identified risk is lower than the actual risk.

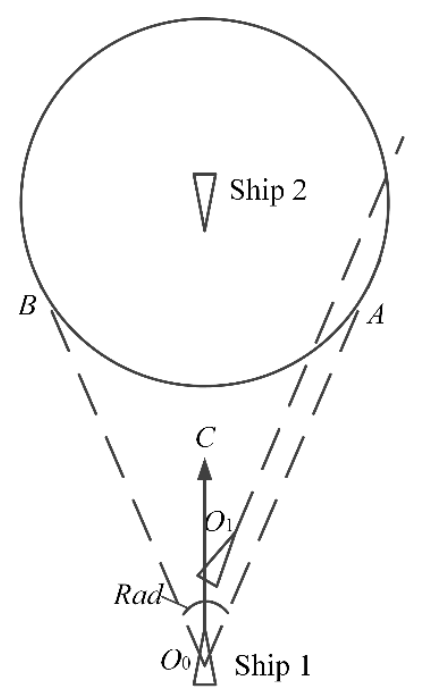

Figure 4. The illustration of possible intruding on the target ship's domain after altering course. 
It can be found that the ship position change from $\mathrm{O}_{0}$ to $\mathrm{O}_{1}$ after considering ship manoeuvrability. When the ship is at $\mathrm{O}_{0}$, the adopted marginal course line O0A can ensure that the ship is free from the target ship's domain. However, if the ship is at $\mathrm{O}_{1}$, the course indicated by $\mathrm{O}_{0} \mathrm{~A}$ cannot make the ship avoid, intruding on the target ship's domain. The course should be further increased in order to be free from the target ship's domain.

Therefore, the danger sector model is improved in order to consider ship manoeuvrability in this paper. This improved danger sector model can make the results of the collision risk more accurate. For integrating ship manoeuvrability into the danger sector model, the turning circle of the ship when conducting a course alteration manoeuvre should be depicted. After determining the ship turning circle, the new position of the ship after turning to the target course can be obtained. For simplification, some assumptions were made to obtain the ship turning circle. First, the first and second phases of ship turning are merged into one phase. In this combined phase, the ship will maintain its original course. Second, for the combined phase, the distance sailed by the ship is equal to $1 / 2$ of advance. This is because the longitudinal distance of the first two phases in the ship turning circle is approximately equal to $1 / 3$ to $1 / 2$ of the advance in many cases [24-28]. The $1 / 2$ of advance is taken to improve the safety criteria. Thirdly, as the advance $A d$ should not exceed 4.5 ship lengths and the tactical diameter $D t$ should not exceed 5 ship lengths in the turning circle manoeuvre [23], the measurement of 4.5 ship lengths was used as a universal advance and 5 ship lengths was used as a universal tactical diameter. The new ship position after considering ship manoeuvrability can be obtained by the following equations:

$$
\begin{gathered}
A_{\mathrm{d}}=4.5 * l_{\mathrm{o}}, \\
x_{1}=x_{0}+0.5 A_{\mathrm{d}} \times \sin c_{\mathrm{o}}+\frac{\left(0.5 A_{\mathrm{d}}-0.5 A_{\mathrm{d}} \times \cos \left(c_{\mathrm{m}}-c_{\mathrm{o}}\right)\right)}{\cos \left(0.5 \times\left(180 \pm\left(c_{\mathrm{m}}-c_{\mathrm{o}}\right)\right)\right)} \times \sin \left(c_{\mathrm{m}}-c_{\mathrm{o}}\right), \\
y_{1}=y_{0}+0.5 A_{\mathrm{d}} \times \cos c_{\mathrm{o}}+\frac{\left(0.5 A_{\mathrm{d}}-0.5 A_{\mathrm{d}} \times \cos \left(c_{\mathrm{m}}-c_{\mathrm{o}}\right)\right)}{\cos \left(0.5 \times\left(180 \pm\left(c_{\mathrm{m}}-c_{\mathrm{o}}\right)\right)\right)} \times \cos \left(c_{\mathrm{m}}-c_{\mathrm{o}}\right),
\end{gathered}
$$

where lo refers to the length of the original ship; $x 0$ and $y 0$ refer to the original longitude and latitude coordinates of the original ship; $x 1$ and $y 1$ refer to the longitude and latitude coordinates of the original ship after considering the ship's manoeuvrability; co refers to the course of the original ship-the actual course of the original ship at the given moment, which is O0C in Figure $4 ; \mathrm{cm}$ refers to the marginal course of the danger sector-compared with $c 0, c \mathrm{~m}$ is a phantom course: the course when the original ship conducts the maximum course alteration in the danger sector, which is $\mathrm{O} 0 \mathrm{~A}$ (for starboard alteration) or $\mathrm{O} 0 \mathrm{~B}$ (for port alteration) in Figure $4 . \pm$ is corresponding to the port or starboard alteration. Figure 5 shows the mechanics of Equations (3) and (4).

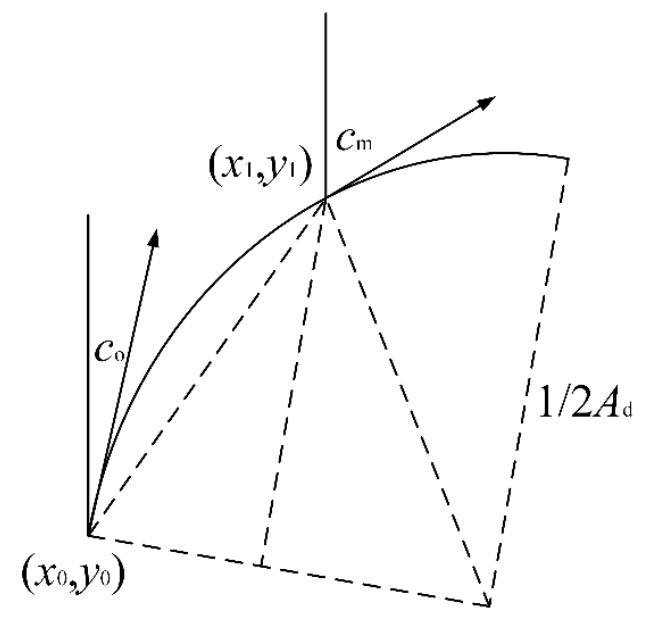

Figure 5. The illustration of Equations (3) and (4). 
After obtaining the new ship position after considering ship manoeuvrability, it should be checked whether the target ship's domain is intruded when the original ship still adopts the marginal course of the danger sector. If the target ship's domain is intruded, the marginal course of the danger sector should be further improved until the own ship can pass free from the target ship's domain. This flow chart is shown in Figure 6.

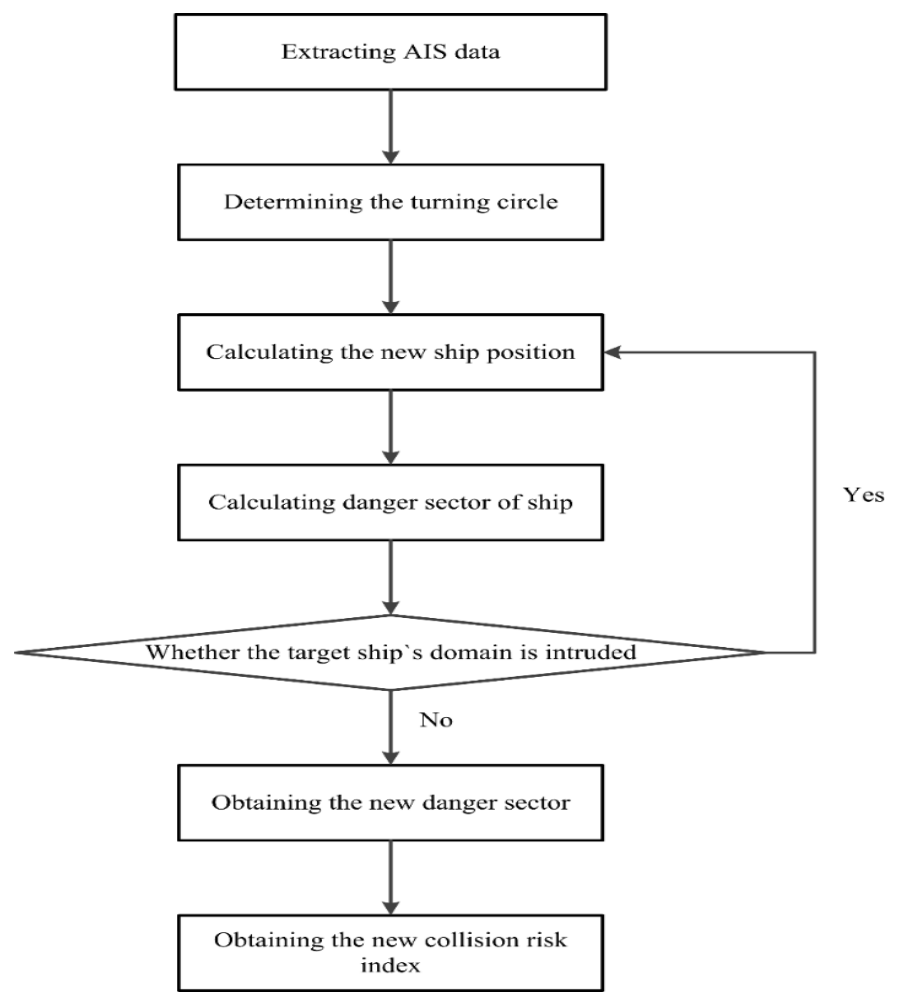

Figure 6. The flow chart of the proposed model.

If the target ship's domain can be passed freely when the original ship adopts the previous marginal course, the danger sector does not need to be adjusted. Otherwise, it should be adjusted to the degree that allows the safe passage of the original ship. The new collision risk index considering ship manoeuvrability can be obtained by the following steps.

1. Calculating the new ship position after considering manoeuvrability

2. Checking that whether the target ship's domain is intruded when the original ship adopts the original danger sector at new position

3. If the target ship's domain is not intruded, the original danger sector is still adopted

4. If the target ship's domain is intruded, adjusting the danger sector until the safe passage of the original ship

5. Obtaining the new danger sector considering ship manoeuvrability

6. Calculating the new collision risk index based on danger sector model in [19]

As the new ship position will decrease the distance between the two ships, the new danger sector considering ship manoeuvrability is normally larger than before, which will lead to the increment of collision risk. In other words, the improved danger sector model will amplify the collision risk value detected, which is helpful for mariners and maritime surveillance operators to identify the collision risk between ships more accurately. 


\section{Case Study}

To validate the improved danger sector proposed in this paper, as well as to show the advantage compared with the original danger sector model, some experiments were carried out in the studied water area. The studied water area is located in the northern Yellow Sea of China, which is near Dalian port. It is located between $38.4^{\circ}$ and $38.7^{\circ} \mathrm{N}, 120.7^{\circ}$ and $121.2^{\circ} \mathrm{E}$. This water area is also known as Bohai Strait, which is one of the three biggest straits in China. As this water area is the connection between the ports around Bohai Sea and the ports in the world, the traffic volume within the water area is relatively big [29]. The heavy maritime traffic can increase the collision risk between ships, which poses a threat to navigational safety. In addition, the varying encounters in this water area can also increase the possibility of collision accidents. Hence, this water area was chosen as the studied water area to validate the proposed model.

To identify the collision risk by the proposed model, the AIS data within the studied water area is used. The AIS data are composed of 27 different types of messages. For calculating the improved danger sector, the dynamic information and static information messages were used. To be more specific, the data of ship position $(x, y)$, ship speed $(v)$, ship course $(c)$, and ship length $(l)$ were extracted from the decoded AIS data, which can form five-dimensional data of $(x, y, v, c, l)$ with a timestamp. To identify the collision risk of a certain encountering of two ships, the data of the two ships should be at the same time. However, as AIS data are not received continuously, we were not able to obtain the data of the two ships at the same time directly. For overcoming this problem, an interpolation method was used to calculate the required ship data at the exact same time.

In order to validate the proposed model sufficiently, the scenarios of all three different types of encountering were selected, which includes head-on encountering, crossing encountering, and overtaking encountering.

The first experiment is a head-on encountering experiment. The encountering two ships sail in approximately opposite directions. The trajectories of the two ships are shown in Figure 7. For each of the ships, 10 sequent moments were selected. The distance between the two ships during these 10 moments are getting closer, which indicates that the collision risk between them continuously grows. This is because the distance is proved to have a negative correlation with collision risk to some extent [10]. For verifying the proposed model of the improved danger sector, the collision risks of these 10 moments were calculated through the proposed method in this paper. To be specific, the collision risk calculated is the collision risk of Ship 2 to Ship 1. The results are shown in Table 1. The distances between the two ships at these moments are also shown in Table 1.

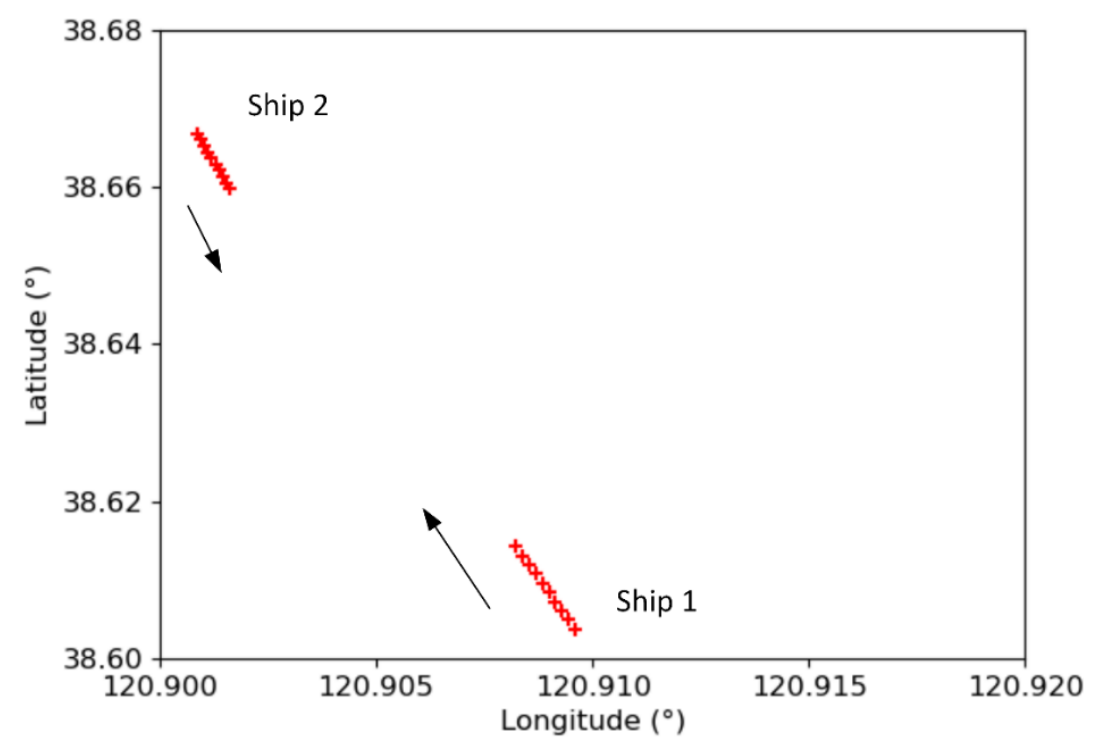

Figure 7. The trajectories of the two encountering ships in a head-on scenario. 
Table 1. The results calculated by the proposed model in a head-on encountering scenario. CRm: collision risk considering ship manoeuvrability, Radm: danger sector considering ship manoeuvrability.

\begin{tabular}{cccccc}
\hline Moment & $\mathbf{1}$ & $\mathbf{2}$ & $\mathbf{3}$ & $\mathbf{4}$ & $\mathbf{5}$ \\
\hline CRm & 0.5770 & 0.5825 & 0.5879 & 0.5959 & 0.6011 \\
Radm & 34 & 35 & 36 & 37.5 & 38.5 \\
Distance & 0.0635 & 0.0616 & 0.0596 & 0.0577 & 0.0557 \\
\hline Moment & $\mathbf{6}$ & $\mathbf{7}$ & $\mathbf{8}$ & $\mathbf{9}$ & $\mathbf{1 0}$ \\
\hline CRm & 0.6113 & 0.6162 & 0.6258 & 0.6329 & 0.6420 \\
Radm & 40.5 & 41.5 & 43.5 & 45 & 47 \\
Distance & 0.0538 & 0.0518 & 0.0499 & 0.0479 & 0.0460 \\
\hline
\end{tabular}

Where $C R \mathrm{~m}$ refers to the collision risk considering ship manoeuvrability, and Radm refers to the danger sector considering ship manoeuvrability. It can be found that the collision risk increases continuously during these 10 moments, which is same as the trend of collision risk reflected by the distance. As the representation of the collision risk, the danger sector during these 10 moments also increases.

For showing the advantage of the proposed model of the improved danger sector, the collision risk and danger sector are also calculated based on the original danger sector model. The results are shown in Table 2.

Table 2. The results calculated by the original model in a head-on encountering scenario. CR: collision risk without considering ship manoeuvrability, Rad: danger sector without considering ship manoeuvrability.

\begin{tabular}{cccccc}
\hline Moment & $\mathbf{1}$ & $\mathbf{2}$ & $\mathbf{3}$ & $\mathbf{4}$ & $\mathbf{5}$ \\
\hline CR & 0.5713 & 0.5770 & 0.5825 & 0.5933 & 0.5985 \\
Rad & 33 & 34 & 35 & 37 & $\mathbf{9}$ \\
\hline Moment & $\mathbf{6}$ & $\mathbf{7}$ & $\mathbf{8}$ & $\mathbf{9}$ & $\mathbf{1 0}$ \\
\hline $\boldsymbol{C R}$ & 0.6037 & 0.6113 & 0.6211 & 0.6282 & 0.6375 \\
Rad & 39 & 40.5 & 42.5 & 44 & 46 \\
\hline
\end{tabular}

Where $C R$ refers to the collision risk without considering ship manoeuvrability, and Rad refers to the danger sector without considering ship manoeuvrability. It can be found that although the results calculated from the original danger sector model also show an upward trend of collision risk, the value of collision risk and the size of the danger sector are smaller than those calculated by the improved danger sector model. This is because the improved danger sector model takes ship manoeuvrability into consideration. After considering ship manoeuvrability, the original danger sector is no longer enough for the original ship to avoid intruding on the target ship's domain. The danger sector should be adjusted upward in order to assess the situation more accurately. In other words, the collision risk obtained by the original danger sector model that fails to consider ship manoeuvrability may be smaller than the actual situation, and this problem can be overcome by the improved danger sector model.

In addition, to further compare the proposed model with the original danger sector model, the manoeuvrability of Ship 1 was changed. The length of Ship 1 was changed to 1.5 times. According to the assumptions in Section 2.2, the advance of Ship 1 will be much longer and the turning circle will be much bigger. Under this situation, the turning manoeuvrability of Ship 1 becomes lower, indicating that the ship is more difficult to alter to the target course and may cause an incrementing danger sector. For verifying the scenario, the danger sector considering ship manoeuvrability and without considering manoeuvrability are both calculated. The results are shown in Table 3. 
Table 3. The danger sector after changing Ship 1's manoeuvrability in a head-on scenario.

\begin{tabular}{|c|c|c|c|c|c|}
\hline Moment & 1 & 2 & 3 & 4 & 5 \\
\hline Radm & 34 & 35 & 36.5 & 38 & 39.5 \\
\hline$R a d$ & 33 & 34 & 35 & 37 & 38 \\
\hline Moment & 6 & 7 & 8 & 9 & 10 \\
\hline Radm & 40.5 & 42.5 & 44 & 46 & 48 \\
\hline Rad & 39 & 40.5 & 42.5 & 44 & 46 \\
\hline
\end{tabular}

Comparing Table 3 with Table 1, it can be clearly found that the danger sector considering ship manoeuvrability becomes larger, which can reflect the change in Ship 1's manoeuvrability. However, the original danger sector does not change compared with Table 2, indicating that it is unable to take the ship manoeuvrability into consideration and fails to distinguish between the two different scenarios with different ship manoeuvrability.

The second experiment is a crossing encountering experiment. The course lines of the two encountering ships are crossed. The trajectories of the two ships are shown in Figure 8. This experiment is carried out as same time as the head-on encountering experiment. Ten moments of each encountering ship were selected. The collision risk, danger sector, and distance of the 10 moments were calculated based on the proposed model, which are shown in Table 4.

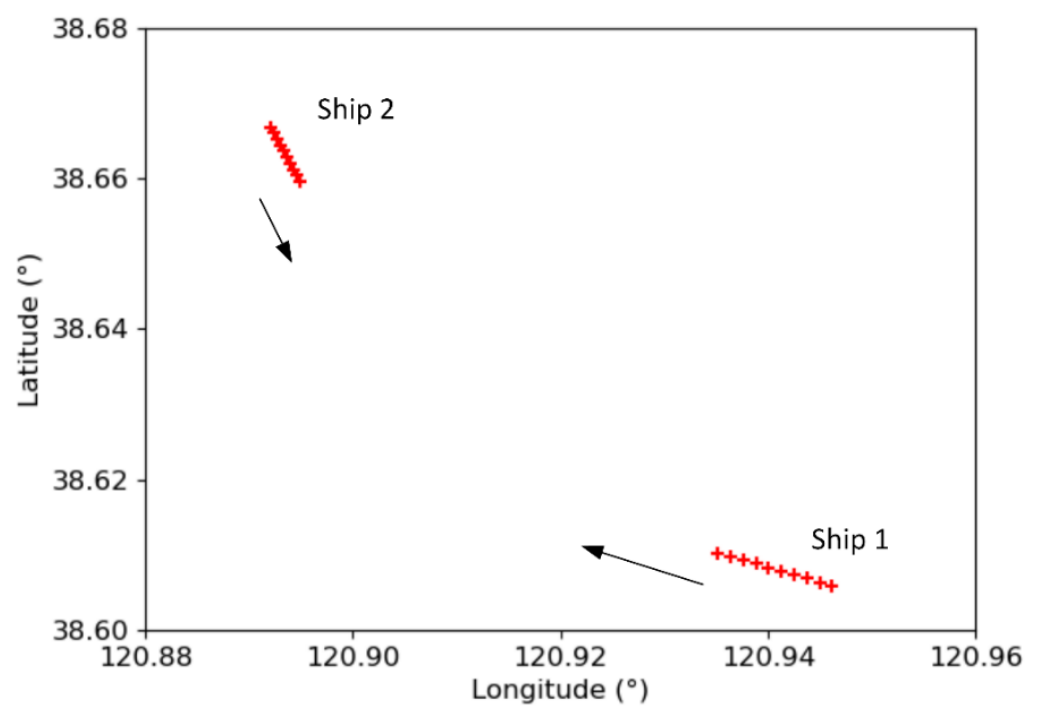

Figure 8. The trajectories of the two encountering ships in a crossing scenario.

Table 4. The results calculated by the proposed model in a crossing encountering scenario.

\begin{tabular}{cccccc}
\hline Moment & $\mathbf{1}$ & $\mathbf{2}$ & $\mathbf{3}$ & $\mathbf{4}$ & $\mathbf{5}$ \\
\hline CRm & 0.5071 & 0.5143 & 0.5178 & 0.5213 & 0.5281 \\
Radm & 23 & 24 & 24.5 & 25 & 26 \\
Distance & 0.0815 & 0.0795 & 0.0775 & 0.0755 & 0.0735 \\
\hline Moment & $\mathbf{6}$ & $\mathbf{7}$ & $\mathbf{8}$ & $\mathbf{9}$ & $\mathbf{1 0}$ \\
\hline CRm & 0.5314 & 0.5379 & 0.5443 & 0.5475 & 0.5566 \\
Radm & 26.5 & 27.5 & 28.5 & 29 & 30.5 \\
Distance & 0.0715 & 0.0695 & 0.0675 & 0.0655 & 0.0636 \\
\hline
\end{tabular}

It can be observed that the collision risk increases continuously during the moments, and the distance during these moments continuously decreases. The collision risk trends reflected by the two 
indicators are the same. As the representation of the collision risk, the danger sector also grows during those moments.

For showing the advantage of the proposed model in crossing encountering, the collision risk and danger sector are also calculated based on the original danger sector model. The results are shown in Table 5 .

Table 5. The results calculated by the original model in a crossing encountering scenario.

\begin{tabular}{cccccc}
\hline Moment & $\mathbf{1}$ & $\mathbf{2}$ & $\mathbf{3}$ & $\mathbf{4}$ & $\mathbf{5}$ \\
\hline CR & 0.4882 & 0.4921 & 0.4998 & 0.4998 & 0.5071 \\
Rad & 20.5 & 21 & 22 & 22 & 23 \\
\hline Moment & $\mathbf{6}$ & $\mathbf{7}$ & $\mathbf{8}$ & $\mathbf{9}$ & $\mathbf{1 0}$ \\
\hline R & 0.5108 & 0.5178 & 0.5213 & 0.5247 & 0.5314 \\
Rad & 23.5 & 24.5 & 25 & 25.5 & 26.5 \\
\hline
\end{tabular}

It can be clearly observed that the collision risk and danger sector without considering ship manoeuvrability are smaller than the values in Table 4 that take turning manoeuvrability into consideration. In other words, the collision risk identified by the original danger sector model is lower than the actual situation, because it fails to incorporate the ship manoeuvrability into the model. It may affect the collision risk monitoring conducted by mariners or maritime surveillance operators to some extent.

In addition, similar to the first experiment, the manoeuvrability of Ship 1 was also changed. The length of Ship 1 was changed to 1.5 times. The ship manoeuvrability is lower than before, and it can lead to the incrementing danger sector. In order to verify this scenario, the danger sectors are calculated by the proposed model and the original model. The results are shown in Table 6.

Table 6. The danger sector after changing Ship 1's manoeuvrability in a crossing scenario.

\begin{tabular}{cccccc}
\hline Moment & $\mathbf{1}$ & $\mathbf{2}$ & $\mathbf{3}$ & $\mathbf{4}$ & $\mathbf{5}$ \\
\hline Radm & 24.5 & 25 & 26 & 26.5 & 27.5 \\
Rad & 20.5 & 21 & 22 & 22 & $\mathbf{9}$ \\
\hline Moment & $\mathbf{6}$ & $\mathbf{7}$ & $\mathbf{8}$ & 31 & $\mathbf{1 0}$ \\
\hline Radm & 28.5 & 29.5 & 30 & 25.5 & 32.5 \\
Rad & 23.5 & 24.5 & 25 & 26.5 \\
\hline
\end{tabular}

It can be found that the danger sector considering ship manoeuvrability is larger than indicated in Table 4, which can reflect the change of Ship 1's manoeuvrability. However, the danger sector without considering ship manoeuvrability remains the same as shown in Table 5. It is unable to distinguish between the two different scenarios with different ship manoeuvrability.

The third experiment is an overtaking encountering experiment. The trajectories of the two encountering ships are shown in Figure 9. There are also 10 moments selected for each ship. However, this overtaking encountering scenario is relatively special. As restricted by the water area, the distance between the two ships are already very close, which is approximately close to the radius of Ship 2's domain. Under this situation, the course alteration manoeuvre may be not enough to allow Ship 1 to not intrude into Ship 2's domain, which is confirmed by the results in Table 7.

It can be found that the distance during these 10 moments decreases gradually, indicating that the collision risk is becoming higher. This trend can also be reflected by the danger sector without considering ship manoeuvrability. However, the danger sector considering ship manoeuvrability is $180^{\circ}$ for all the 10 moments, which means that the danger sector has reached the set maximum value. This is because the distance between the two ships is very close under the water area restriction as stated above. If the ship manoeuvrability is not considered, Ship 1 still has the chance to avoid intruding into 
Ship 2's domain by course alteration. However, if the ship manoeuvrability is considered, the distance between the two ships will be much closer, which will lead to the situation in which conducting only a course alteration manoeuvre is no longer effective. Under this situation, Ship 1 should conduct a speed reduction manoeuvre combined with a course alteration manoeuvre in order to avoid intruding into Ship 2's domain. Nevertheless, the two kinds of danger sector showed in Table 7 also prove that the danger sector considering ship manoeuvrability can reflect the collision risk of an actual situation more accurately than the danger sector without considering ship manoeuvrability. To obtain the detailed collision risk values, the proposed model of an improved danger sector can be combined with the model in [30], which incorporates speed reduction into the danger sector model.

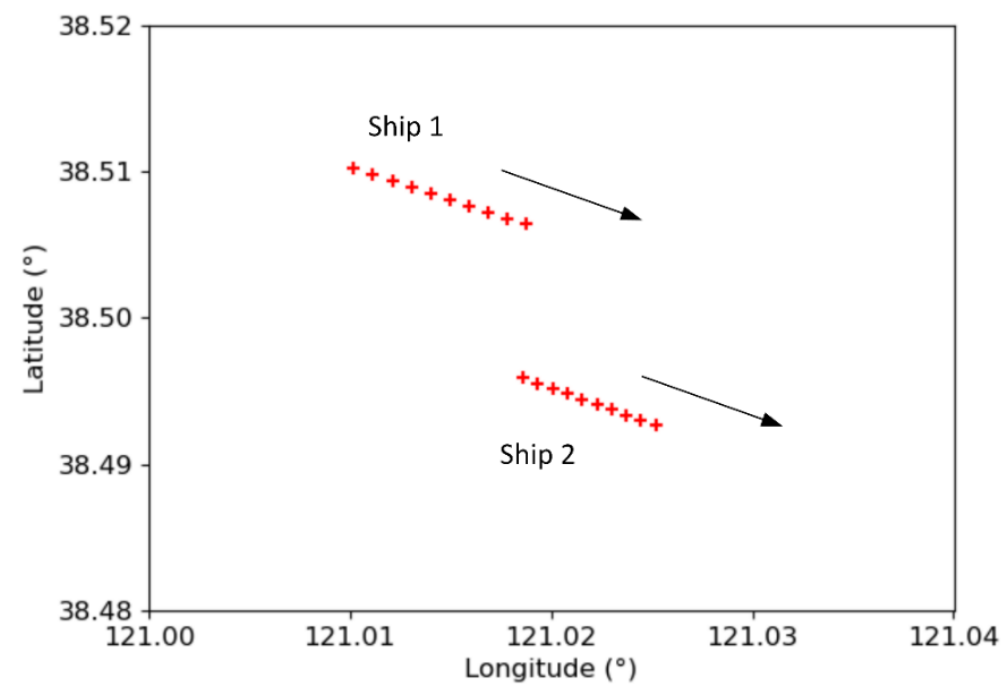

Figure 9. The trajectories of the two encountering ships in an overtaking scenario.

Table 7. The results in an overtaking encountering scenario.

\begin{tabular}{cccccc}
\hline Moment & $\mathbf{1}$ & $\mathbf{2}$ & $\mathbf{3}$ & $\mathbf{4}$ & $\mathbf{5}$ \\
\hline CRm & 180 & 180 & 180 & 180 & 180 \\
Radm & 30 & 31 & 32.5 & 33.5 & 35 \\
Distance & 0.0166 & 0.0164 & 0.0163 & 0.0161 & 0.0159 \\
\hline Moment & $\mathbf{6}$ & $\mathbf{7}$ & $\mathbf{8}$ & $\mathbf{9}$ & $\mathbf{1 0}$ \\
\hline CRm & 180 & 180 & 180 & 180 & 180 \\
Radm & 36.5 & 38.5 & 40 & 42.5 & 45 \\
Distance & 0.0158 & 0.0156 & 0.0155 & 0.0153 & 0.0152 \\
\hline
\end{tabular}

After carrying out the above experiments, it can be concluded that the proposed model of the improved danger sector can take manoeuvrability into consideration and is effective at identifying the collision risk between two encountering ships. In addition, it can represent the collision risk of the actual situation more accurately than the original danger sector model, which is very helpful for mariners and maritime surveillance operators to assess the collision risk in the water area.

\section{Discussion}

This paper proposed an improved danger sector model that can identify the collision risk between two encountering ships. The proposed model was improved from the danger sector model to take ship manoeuvrability into consideration. When calculating the danger sector of a ship, the turning circle should be determined based on its manoeuvrability. The incorporation of ship manoeuvrability will change the ship position when it reaches the target marginal course of the original danger sector. Normally, the danger sector should be adjusted further in order to avoid the original ship intruding into 
the target ship's domain, which will increase the collision risk between the ships. When considering ship manoeuvrability, the improved danger sector model can identify the collision risk between ships more accurately.

In Section 3, the improved danger sector model is validated by three different experiments. The model proved that it can identify the collision risk effectively and more accurately. Apart from this, there is still a characteristic that can be found in this improved danger sector model-that is, the magnitude of the increase of the danger sector increases with the reduction of distance. In other words, with the collision risk becoming higher, the improved danger sector model can be more effective and superior. The change of the danger sector size $\Delta R a d$ was used to evaluate this phenomenon. $\Delta R a d$ is the difference value between Radm and Rad, which can be expressed as the following equation:

$$
\Delta R a d=R a d_{m}-\Delta R a d
$$

It is the difference between the danger sectors before and after considering ship manoeuvrability. For the head-on encountering scenario, the $\Delta$ Rad of 10 moments were calculated as shown in Table 8 . In addition, the overlapping of collision risk is also used to check this characteristic. Collison is implied when the overlapping collision risk is growing. In the proposed model, the overlapping of collision risks can be represented by the overlapping danger sectors. The overlapping results are also shown in Table 8.

Table 8. The difference of danger sectors before and after considering manoeuvrability in a head-on encountering scenario.

\begin{tabular}{cccccc}
\hline Moment & $\mathbf{1}$ & $\mathbf{2}$ & $\mathbf{3}$ & $\mathbf{4}$ & $\mathbf{5}$ \\
\hline $\boldsymbol{\Delta R a d}$ & 1 & 1 & 1 & 0.5 & 0.5 \\
Overlap & 33 & 34 & 35 & 37 & $\mathbf{3}$ \\
\hline Moment & $\mathbf{6}$ & $\mathbf{7}$ & $\mathbf{8}$ & 1 & $\mathbf{1 0}$ \\
\hline $\boldsymbol{\Delta R a d}$ & 1.5 & 1 & 1 & 44 & 1 \\
Overlap & 39 & 40.5 & 42.5 & 46 \\
\hline
\end{tabular}

It can be calculated that the average $\Delta R a d$ of the last 5 moments is 1375 , which is larger than the average $\Delta R a d$ of the first 5 moments, which is 1 . For the overlapping danger sectors, the average of the last 5 moments is 42.4 , which is larger than the average of the first 5 moments, which is 35.4 . This can be also presented in the crossing scenario in Table 9.

Table 9. The difference of danger sectors before and after considering manoeuvrability in a crossing encountering scenario.

\begin{tabular}{|c|c|c|c|c|c|}
\hline Moment & 1 & 2 & 3 & 4 & 5 \\
\hline$\Delta R a d$ & 3.5 & 3 & 2.5 & 3 & 3 \\
\hline Overlap & 20.5 & 21 & 22 & 22 & 23 \\
\hline Moment & 6 & 7 & 8 & 9 & 10 \\
\hline$\Delta R a d$ & 3 & 3 & 3.5 & 3.5 & 3.5 \\
\hline Overlap & 23.5 & 24.5 & 25 & 25.5 & 26.5 \\
\hline
\end{tabular}

Where the average $\Delta R a d$ of the last 5 moments is 4125 , which is larger than the average $\Delta R a d$ of the first 5 moments, which is 3.75 . For the overlapping danger sector, the average of the last 5 moments is 25 , which is larger than the average of the first 5 moments, which is 21.7. For furthering proving this relationship, another 10 moments after the moments in Figure 7 were selected. During these 10 moments, the distance between the two encountering ships is much closer. The ship trajectories for these 10 moments are shown in Figure 10. The danger sectors before and after considering the ship manoeuvrability are shown in Table 10. 


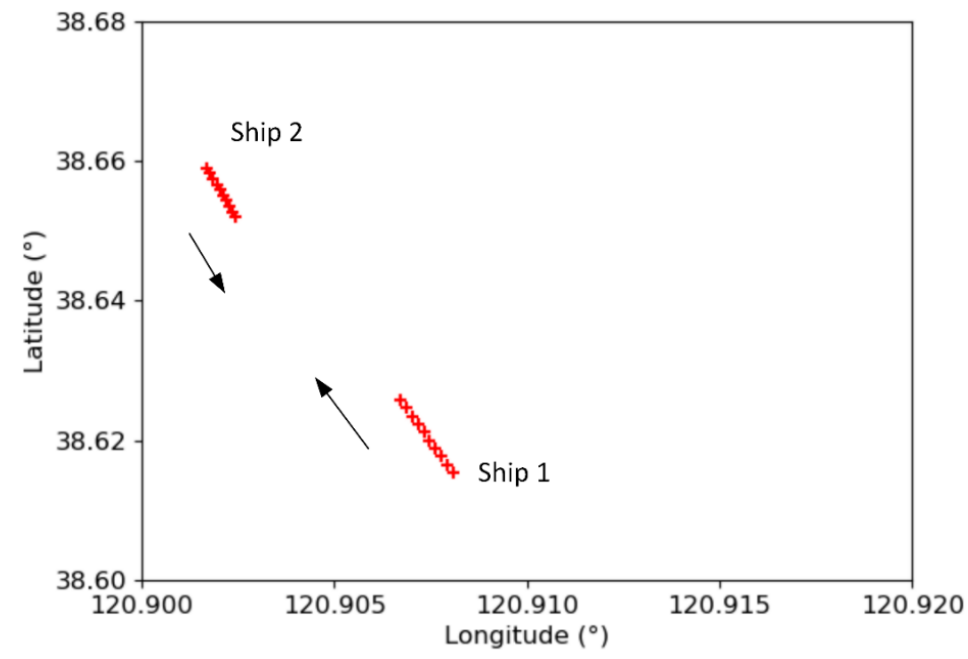

Figure 10. The trajectories of two head-on encountering ships for another 10 moments.

Table 10. The danger sectors of another 10 moments in a head-on encountering scenario.

\begin{tabular}{cccccc}
\hline Moment & $\mathbf{1}$ & $\mathbf{2}$ & $\mathbf{3}$ & $\mathbf{4}$ & $\mathbf{5}$ \\
\hline Radm & 49 & 52 & 54 & 57 & 60 \\
Rad & 48 & 50.5 & 52.5 & 55.5 & 58.5 \\
$\Delta$ Rad & 1 & 1.5 & 1.5 & 1.5 & 1.5 \\
\hline Moment & $\mathbf{6}$ & $\mathbf{7}$ & $\mathbf{8}$ & $\mathbf{9}$ & $\mathbf{1 0}$ \\
\hline Radm & 63.5 & 67.5 & 72 & 76.5 & 82.5 \\
Rad & 62 & 65.5 & 70 & 75 & 80.5 \\
$\Delta$ Rad & 1.5 & 2 & 2 & 1.5 & 2 \\
\hline
\end{tabular}

It can be calculated that the average $\Delta R a d$ of the first 5 moments is 1.75 , which is larger than the average $\Delta R a d$ of the last 5 moments in Table 8 , which is 1.375 , and the average $\Delta R a d$ of the last 5 moments in Table 10 is 2.25 , which is much larger. This can be also reflected by the crossing scenario. Another 10 moments after the moments in Figure 8 were selected. During these 10 moments, the distance between the two encountering ships is closer. The ship trajectories for these 10 moments are shown in Figure 11. The danger sectors before and after considering ship manoeuvrability are shown in Table 11.

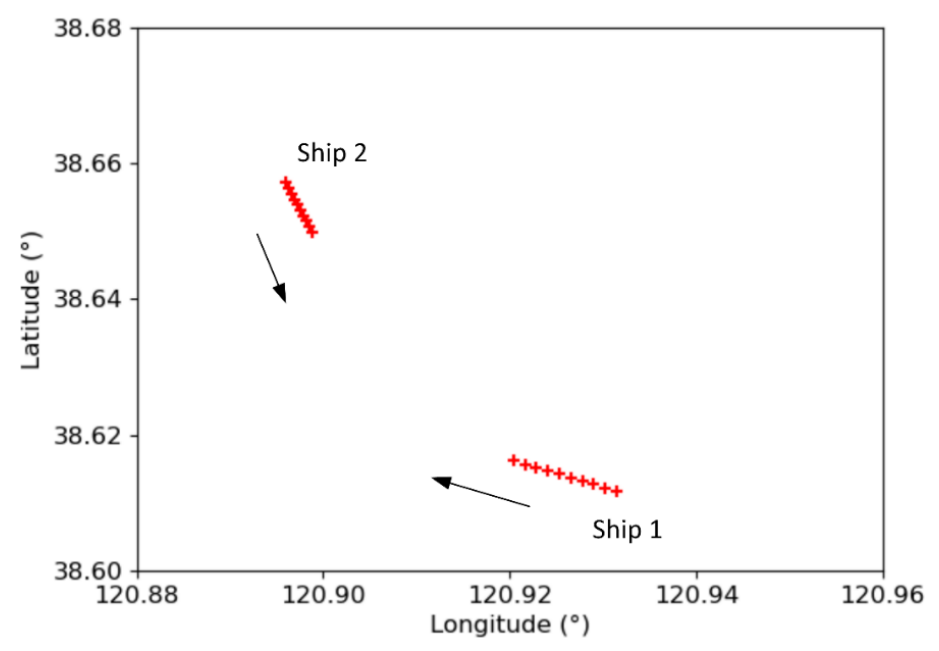

Figure 11. The trajectories of two crossing encountering ships for another 10 moments. 
Table 11. The danger sectors of another 10 moments in a crossing encountering scenario.

\begin{tabular}{cccccc}
\hline Moment & $\mathbf{1}$ & $\mathbf{2}$ & $\mathbf{3}$ & $\mathbf{4}$ & $\mathbf{5}$ \\
\hline Radm & 33.5 & 35 & 36.5 & 38 & 39.5 \\
Rad & 29.5 & 30 & 31.5 & 32.5 & 34 \\
$\Delta$ Rad & 4 & 5 & 5 & 5.5 & 5.5 \\
\hline Moment & $\mathbf{6}$ & $\mathbf{7}$ & $\mathbf{8}$ & 45 & $\mathbf{1 0}$ \\
\hline Radm & 41 & 36.5 & 39 & 40.5 & 49.5 \\
Rad & 35 & 6 & 6 & 7 & 42.5 \\
$\Delta$ Rad & 6 & & & 7 & 7 \\
\hline
\end{tabular}

It can be calculated that the average $\Delta R a d$ of the first 5 moments is 6.25 , which is larger than the average $\Delta R a d$ of the last 5 moments in Table 9, which is 4.125 , and the average $\Delta R a d$ of the last 5 moments in Table 11 is 8 , which is much larger. The results above can prove that the magnitude of the increase of the danger sector increases with the reduction of distance-that is, the improved danger sector model can be more effective than the original danger sector model with the increase of the collision risk. This phenomenon is not difficult to be explained. When the distance between two encountering ships become closer, it is more difficult for the ship to conduct a course alteration manoeuvre to avoid intruding into the target ship's domain, because there is less room for course alteration. Therefore, the more dangerous the scenario, the greater the difference between the improved danger sector model and the original danger sector model, and the more effective and superior the proposed model of the improved danger sector. Using this improved danger sector model, mariners and maritime surveillance operators can assess the collision risk between ships in the water area more accurately, especially in dangerous situations.

Nevertheless, the proposed model of the improved danger sector still has some limitations. Firstly, for determining the turning circle of a ship, some assumptions in Section 2.2 were made for simplification, such as merging the first two phases of the turning circle into a simple straight path and using the IMO minimum criteria for turning manoeuvrability as the universal parameters. Actually, the first two phases of the turning circle are much more complicated with many ship motion parameters involved. In addition, the determination of the advance and tactical diameter is more complicated. The determination of the parameters of the turning circle is a very complicated process, which involves many ship parameters. Taking the first two phases in the turning circle as an example-namely, the manoeuvring and evolutionary phases, the proposed model merges them into one phase, indicating that the ship will sail directly in this phase and the distance is related to the preset parameter $A \mathrm{~d}$. Actually, in the manoeuvring phase, the distances sailed by different ships and the duration are normally different. In the evolutionary phase, a tiny shift will be formed to the opposite direction of the rudder angle. The ship moves in a curve in this phase, but not straight forward as assumed in the proposed model, and the curvature of the curve may be varied for different ships. That is to say, for different ships with different parameters, the duration, displacement, and parameters related to the phases may be varied. The proposed model simplified this process. It can decrease the calculation complexity obviously, but it also results in the obtained parameters of the turning circle not being accurate enough. For obtaining the two important parameters $A \mathrm{~d}$ and $\mathrm{Td}$ in the turning circle, the proposed model uses the IMO standards for ship manoeuvrability. The standard for $A \mathrm{~d}$ and $T \mathrm{~d}$ is a kind of minimum requirement, so they can only be estimated approximately by using this standard. Actually, in many ship manoeuvrability reseach studies, for obtaining the accurate values of $A \mathrm{~d}$ and $T \mathrm{~d}$, researchers should use a very complicated computation or relatively complicated experiment [24-28]. Under the assumptions in this paper, the turning circle and the ship position can only be estimated approximately. Generally, the rudder angle can influence the turning circle. The parameters of the turning circle are varied with different rudder angles. The proposed model is established based on the simplified assumptions. In the first two phases, the distance sailed by the ship is related to the preset parameter $A \mathrm{~d}$. In the third phase, the calculation of the turning circle is 
also based on the preset $A \mathrm{~d}$, which is determined by the IMO standards for ship manoeuvrability. Therefore, the actual rudder angle is not considered in the modelling. This can also be considered as a limitation of the proposed model. Therefore, based on the limitations mentioned above, the proposed model can be improved in the following aspects. Firstly, the model can treat the first two phases of the turning circle as two separate phases. Secondly, the parameters of the turning circle can be calculated or examined more accurately through considering ship motion parameters, such as the determination of $A \mathrm{~d}$ and $T \mathrm{~d}$. If these parameters can be determined more accurately, the collision risk value will also be more accurate. Thirdly, although a more accurate calculation of turning circle parameters is suggested above, the calculation complexity should also be considered. It is better to combine some related methods with the proposed model in order to establish a method that can balance the accuracy of the results and the complexity of the calculation, which can improve the practical applicability of the proposed model and make it convenient to handle in the practical scenario. Secondly, the proposed model is relatively limited to a restricted water area, such as a traffic separation scheme. The overtaking scenario in Section 3 is a typical example. In such a water area, as the distance between two ships may be very close, the danger sector considering ship manoeuvrability may reach the maximum set value and thus fails to obtain the exact collision risk values. This problem can be solved by combining the proposed model with the danger sector model considering speed reduction. Besides, some restricted water areas may affect the manoeuvrability of the ship, such as a narrow channel, traffic separation scheme, shallow water, etc. When ship is sailing in these restricted water areas, the manoeuvrability is usually limited by the characteristics of these water areas. Generally, the ship is not capable of conducting a collision avoidance manoeuvre as efficient as in unrestricted and deep water. It is usually more difficult for the ship to carry out a course alteration manoevure to avoid collision. The proposed model was established based on the standards for ship manoeuvrability that apply in unrestricted and deep water. Therefore, if the proposed model is used to assess the collision risk in restricted water, the results may be not accurate enough. This is also a limitation of the proposed model brought by the restricted water area. For assessing the collision risk in a restricted water area, the characteristic of the water area should be considered, and an additional analysis should be made regarding the impact of the characteristic of the water area on ship manoeuvrability. Thirdly, the ship domain used in the proposed model is still a simplified circle domain. In fact, the shape of the ship domain is more like an ellipse in most instances. For further improving the precision of the results, the elliptical domain can be used in future research.

\section{Conclusions}

Herein, an improved danger sector model considering ship manoeuvrability was proposed, which can identify the collision risk between two encountering ships in the water area. Compared with the original danger sector model, the proposed model takes ship manoeuvrability into consideration when determining the size of the danger sector. To consider ship manoeuvrability, the turning circle of the ship when conducting a course alteration manoeuvre is depicted under related assumptions. After considering manoeuvrability, the ship position will be changed, and the danger sector will be adjusted upward. To validate the proposed improved danger sector model, some experiments of different encountering scenarios were carried out by using the AIS data in the northern Yellow Sea of China. The results show that the proposed model can identify the collision risk between two encountering ships efficiently and can assess the collision risk more accurately than the original model, especially in a dangerous scenario. The proposed model can assist mariners and maritime surveillance operators in conducting a more effective and accurate identification of ship collision risk so as to improve navigation safety.

The proposed model also has some limitations, which should be improved further in the future research. Firstly, the turning circle in the proposed model is determined under some simplified assumptions. Actually, the determination of the turning circle of a ship is much more complicated. Secondly, the proposed model is relatively limited to a restricted water area such as a traffic separation 
scheme, and it can be combined with other models in the future study. Thirdly, the ship domain used in the proposed model is a circular domain. In future study, an elliptical one can be used to further improve the precision of the results.

Author Contributions: Conceptualisation, Z.L.; Methodology, Z.L.; Software, Z.L.; Validation, Z.L.; Formal Analysis, Z.L.; Investigation, Z.L.; Resources, Z.W., Z.Z.; Data Curation, Z.L.; Writing-Original Draft Preparation, Z.L.; Writing-Review and Editing, Z.L., Z.W., Z.Z.; Visualisation, Z.L.; Supervision, Z.W., Z.Z.; Project Administration, Z.L.; Funding Acquisition, Z.L. All authors have read and agreed to the published version of the manuscript.

Funding: This work was supported by "Double First-class" Construction Project of Dalian Maritime University ("Innovation Project") (Grant. BSCXXM003).

Acknowledgments: We would like to express our gratitude to the editors and reviewers whose valuable comments and suggestions will make an improvement of the quality of this paper.

Conflicts of Interest: The authors declare no conflict of interest.

\section{References}

1. Schinas, O.; Psaraftis, H.N. New frontiers through shortsea shipping. In Transactions—The Society of Naval Architects and Marine Engineers; SNAME: Alexandria, VA, USA, 1997.

2. Psaraftis, H.N.; Kontovas, C.A. Balancing the economic and environmental performance of maritime transportation. Transp. Res. Part D Transp. Environ. 2010, 15, 458-462. [CrossRef]

3. Guedes Soares, C.; Teixeira, A.P. Risk assessment in maritime transportation. Reliab. Eng. Sys. Saf. 2001, 74, 299-309. [CrossRef]

4. Wu, B.; Yan, X.; Wang, Y.; Guedes Soares, C. An evidential reasoning-based CREAM to human reliability analysis in maritime accident process. Risk Anal. 2017, 37, 1936-1957. [CrossRef] [PubMed]

5. Ni, S.; Liu, Z.; Cai, Y. Ship manoeuvrability-based simulation for ship navigation in collision situations. J. Mar. Sci. Eng. 2019, 7, 90. [CrossRef]

6. Zhao, Y.; Xue, M. Ship Manoeuvring and Collision Avoidance, 1st ed.; Dalian Maritime University Press: Dalian, China, 2012; pp. 1-2. (In Chinese)

7. Wen, Y.; Huang, Y.; Zhou, C.; Yang, J.; Xiao, C.; Wu, X. Modelling of marine traffic flow complexity. Ocean Eng. 2015, 104, 500-510. [CrossRef]

8. Kearon, J. Computer program for collision avoidance and track keeping. In Proceedings of the International Conference on Mathematics Aspects of Marine Traffic, London, UK, 1977.

9. Zhao, J.; Song, S. Measurement of the mariners' subjective collision risks. J. Dalian Mar. Coll. 1990, 16, $29-31$. (In Chinese)

10. Lisowski, J. Determining the optimal ship trajectory in collision situation. In Proceedings of the IX International Scientific and Technical Conference on Marine Traffic Engineering, Szczecin, Poland, 2001.

11. Kao, S.; Lee, K.; Chang, K.; Ko, M. A fuzzy logic method for collision avoidance in vessel traffic service. J. Navig. 2007, 60, 17-31. [CrossRef]

12. Schinas, O. Examining the use and application of multi-criteria decision making techniques in safety assessment. In Proceedings of the International Symposium on Maritime Safety, Security \& Environmental Protection, Athens, Greece, 20-21 September 2007.

13. Bukhari, A.C.; Tusseyeva, I.; Lee, B.; Kim, Y. An intelligent real-time multi-vessel collision risk assessment system from VTS view point based on fuzzy inference system. Expert. Sys. Appl. 2013, 40, 1220-1230. [CrossRef]

14. Zhang, W.; Goerlandt, F.; Kujala, P.; Wang, Y. An advanced method for detecting possible near-miss ship collisions from AIS data. Ocean Eng. 2016, 124, 141-156. [CrossRef]

15. Zhang, W.; Kopca, C.; Tang, J.; Ma, D.; Wang, Y. A systematic approach for collision risk analysis based on AIS data. J. Navig. 2017, 70, 1117-1132. [CrossRef]

16. Chen, P.; Huang, Y.; Mou, J.; van Gelder, P.H.A.J.M. Ship collision candidate detection method: A velocity obstacle approach. Ocean Eng. 2018, 170, 186-198. [CrossRef]

17. Fang, Z.; Yu, H.; Ke, R.; Shaw, S.; Peng, G. Automatic identification system-based approach for assessing the near-miss collision risk dynamics of ships in ports. IEEE Trans. Intell. Transp. Sys. 2019, 20, 534-543. [CrossRef] 
18. Li, Y.; Liu, Z.; Kai, J. Study on complexity model and clustering method of ship to ship encountering risk. J. Mar. Sci. Technol. 2019, 27, 153-160. [CrossRef]

19. Liu, Z.; Wu, Z.; Zheng, Z. A cooperative game approach for assessing the collision risk in multi-vessel encountering. Ocean Eng. 2019, 187, 106175. [CrossRef]

20. Liu, D.; Wang, X.; Cai, Y.; Liu, Z.; Liu, Z. A novel framework of real-time regional collision risk prediction based on the RNN approach. J. Mar. Sci. Eng. 2020, 8, 224. [CrossRef]

21. Liu, Z.; Wu, Z.; Zheng, Z. A novel framework for regional collision risk identification based on AIS data. Appl. Ocean Res. 2019, 89, 261-272. [CrossRef]

22. Turning Circle. Available online: https://encyclopedia2.thefreedictionary.com/turning+circle (accessed on 15 July 2020).

23. International Maritime Organization (IMO). Standards for Ship Manoeuvrability; Resolution MSC. 137(76); International Maritime Organization: London, UK, 2002.

24. Fang, M.; Luo, J.; Lee, M. A nonlinear mathematical model for ship turning circle simulation in waves. J. Ship Res. 2005, 49, 69-79.

25. Liang, L.; Zhao, P.; Zhang, S.; Yuan, J. Simulation analysis of fin stabilizers on turning circle control during ship turns. Ocean Eng. 2019, 173, 174-182. [CrossRef]

26. Zhao, P.; Liang, L.; Zhang, S.; Ji, M.; Yuan, J. Simulation analysis of rudder roll stabilization during ship turning motion. Ocean Eng. 2019, 189, 106322. [CrossRef]

27. Broglia, R.; Dubbioso, G.; Durante, D.; Di Mascio, A. Simulation of turning circle by CFD: Analysis of different propeller models and their effect on manoeuvring prediction. Appl. Ocean Res. 2012, 39, 1-10. [CrossRef]

28. Broglia, R.; Durante, D.; Dubbioso, G.; di Mascio, A. Turning ability characteristics study of a twin screw vessel by CFD. In Proceedings of the Marine ECCOMAS, Lisbon, Portugal, 28-30 September 2011.

29. Liu, J.; Han, X. Survey and analysis of vessel traffic flow in the Bohai Strait. Ship Ocean Eng. 2008, 37, 95-98. (In Chinese)

30. Liu, Z.; Wu, Z.; Zheng, Z. A collision avoidance manoeuvre and ship domain based model for identifying collision risk index between ships. In Proceedings of the 2019 4th International Conference on System Reliability and Safety (ICSRS), Rome, Italy, 20-22 November 2019. [CrossRef]

(C) 2020 by the authors. Licensee MDPI, Basel, Switzerland. This article is an open access article distributed under the terms and conditions of the Creative Commons Attribution (CC BY) license (http://creativecommons.org/licenses/by/4.0/). 